\title{
Coagulation studies in haemophilic patients taking oral contraceptives
}

\author{
A. L. BLOOM, PETER BECK, J. C. GIDDINGS, AND P. M. SWEETNAM \\ From the Department of Haematology and Medical Unit, Royal Infirmary, Cardiff, and the MRC \\ Epidemiological Research Unit, Cardiff
}

SYNOPSIS Coagulation studies were performed on haemophilic patients during a controlled trial of oral contraceptive therapy. Treatment with a combined oestrogen-progestogen preparation was associated with a significant rise in the factor VII-X complex. This change was not observed during treatment with progestogen alone. The highest levels of factor IX and fibrinogen and the lowest levels of factor $\mathrm{X}$ were observed during the first period of the trial but these effects were independent of the type of treatment. The results suggest that the effects of oral contraceptives on blood coagulation in haemophilic males are similar to those observed in normal females and that the changes are due to the oestrogenic component.

The administration of oral contraceptive agents is associated with increased incidence of thromboembolic phenomena in women of childbearing age (Medical Research Council, 1967). Because of this association, studies have been undertaken to detect the effect of these preparations on blood coagulation factors. Although increased levels of fibrinogen (Phillips, Turksoy, and Southam, 1961) and factor VIII (Egeberg and Owren, 1963) have been reported, raised levels of the vitamin $\mathrm{K}$-dependent coagulation factors, prothrombin, factor VII, and factor X have been most consistently observed (Rutherford, Hougie, Banks, and Coburn, 1964; Donayre and Pincus, 1965; Miller, Lee, and Ritz, 1965; Thomson and Poller, 1965; Poller and Thomson, 1966). Most of these reports have concerned the response to combined oestrogen-progestogen preparations, but Poller, Thomson, Tabiowo, and Priest (1969) made the important observation that a preparation containing only progestogen caused no rise in factors VII and X. Furthermore, the raised levels of these coagulation factors in women already taking a combined preparation tended to revert to normal when they changed to progestogen alone.

Following the report of Özsoylu and Çorbacioglu (1967) that oral contraceptive agents are beneficial in haemophilia, we have assessed the effect of an oestrogen-progestogen preparation and progestogen alone in such patients. Our results, with regard to factor VIII levels and clinical response, were not Received for publication 10 June 1970. encouraging and have been published elsewhere (Beck, Bloom, Giddings, and Sweetnam, 1970). In view of the reported effects of these hormones on blood coagulation in women and because of the possibility that these changes may not be induced by progestogen alone the opportunity was taken to study the changes in coagulation factors other than factor VIII. These results are now reported. It will be shown that in haemophiliacs treatment with an oestrogen-progestogen preparation was associated with raised levels of factor VII-X complex, but that this was not so during treatment with progestogen alone.

\section{Methods}

\section{TREATMENT AND TRIAL DESIGN}

The oral contraceptive preparation used by Özoylu and Çorbacioglu (1967) contained lynestranol $2.5 \mathrm{mg}$ and mestranol $0.075 \mathrm{mg}$ (Lyndiol 2.5). This was used as the combined preparation for the present study also. Because it was thought that elevations of coagulation factors are due to the oestrogenic component alone and in order to evaluate this we decided to compare two 'active' compounds, namely, the combined preparation and an identical tablet containing only lynestranol, $2.5 \mathrm{mg}$, with a lactose placebo.

The trial was of triple cross-over design and the prescribing of treatment was double blind. Every patient received each of the three treatments for a period of 12 weeks, with a four-week interval between 
different therapies; the trial thus lasted 44 weeks. There were six possible orders in which the three treatments could be given. The allocation of the treatments to the patients was random, subject to the constraint that each of the six possible orders was received by three patients. This ensured that the treatments and the order of their administration were independent and that their effects could be considered separately.

Eighteen postpubertal males with classical haemophilia took part in the trial. Their ages ranged from 16 to 59 and their informed consent, and where necessary that of their parents, was obtained before they entered the study. Twelve of the patients were severely affected (factor VIII $0-1 \%$ ) and six moderately or mildly affected (factor VIII $2-15 \%$ ). Blood samples were taken before the start of the trial and thereafter at four-weekly intervals.

\section{COAGULATION STUDIES}

Factor $\mathrm{X}$ assays were performed by the method of Denson (1961) using charcoal-adsorbed substrate plasma and Russell viper venom-cephalin mixture (Diagnostic Reagents Ltd).

Factor VII-X complex was assayed in a similar manner to factor $X$ but saline extract of brain (Biggs and Macfarlane, 1962) was substituted for the venom-cephalin mixture.

Factor IX was assayed by a one-stage method similar to that described by Hardisty and Ingram (1965) utilizing a kaolin-activated system consisting of stored $\left(-30^{\circ} \mathrm{C}\right)$ plasma from a patient with severe factor IX deficiency, adsorbed fresh normal plasma to supply factors V and VIII, and phospholipid.

All the above coagulation factor assays were standardized on each occasion against a pool of six fresh normal plasma samples.

Plasma fibrinogen was estimated as thrombinclottable protein as described by Varley (1967). The protein digest was estimated with FolinCiocalteu reagent using a tyrosine (AnalaR) standard.

The factor IX assays and plasma fibrinogen levels were performed during the trial on plasma samples stored at $-30^{\circ} \mathrm{C}$ for less than one week. The factor $\mathrm{X}$ and factor VII-X assays were performed at the termination of the trial on plasma samples stored at $-30^{\circ} \mathrm{C}$ for variable periods of time. All assays were performed 'blind', that is, without knowledge of the treatment received by the patients.

STATISTICAL ANALYSIS

The results were analysed using a standard two-way analysis of variance which separated out the treatment effect, the treatment period (first, second, or third) effect, and the patient effect.

\section{Results}

The mean values of the various coagulation factors during each treatment are shown in Table I. The levels of the factor VII-X complex were significantly raised on the combined preparation compared with those observed during treatment with placebo or progestogen alone $(P<0.01$ in each case). The level of factor $X$, on the other hand, was lower during treatment with progestogen alone than with either of the other two treatments, but the differences were not marked and were only significant $(P<0.05)$ when compared with the combined preparation. There were no significant differences in the levels of factor IX and fibrinogen.

The mean values of the various coagulation factors during each of the three 12-week treatment periods are shown in Table II. For all factors, except VII-X, there was a highly significant $(P<0.01)$ change in the mean levels with the treatment period. For factor IX and fibrinogen the mean levels in the third period (December 1968-February 1969) were only $63 \%$ and $72 \%$ respectively of those in the first period (May 1968-July 1968). In both cases the mean levels in the second period were intermediate, indicating a steady decrease with time. For factor $\mathrm{X}$ the position was reversed, the mean level in the third period being $29 \%$ higher than that in the first, the level in the second period again being intermediate.

\begin{tabular}{llcr}
\hline $\begin{array}{l}\text { Clotting } \\
\text { Factor }\end{array}$ & \multicolumn{3}{l}{ Mean Value on Each Treatment $(\%)$} \\
\cline { 2 - 4 } & Placebo & Progestogen & Combined \\
\hline VII + X & $125.5(51)$ & $115.8(52)$ & $141.8(52)$ \\
IX & $88.6(51)$ & $86.9(54)$ & $93.5(53)$ \\
X & $91.5(51)$ & $81.7(52)$ & $93.2(52)$ \\
Fibrinogen (mg) & $381.3(51)$ & $398.6(54)$ & $380.6(53)$ \\
\hline
\end{tabular}

Table I Mean values of clotting factors on each treatment

${ }^{1}$ The number of estimations on which the mean levels are based is given in brackets. Statistical significances are given in the text.

\begin{tabular}{|c|c|c|c|}
\hline \multirow{2}{*}{$\begin{array}{l}\text { Clotting } \\
\text { Factor }\end{array}$} & \multicolumn{3}{|c|}{ Mean Value during Treatment Period (\%) } \\
\hline & $\begin{array}{l}\text { First } \\
\text { (May to } \\
\text { July 1968) }\end{array}$ & $\begin{array}{l}\text { Second } \\
\text { (September to } \\
\text { November } \\
1968 \text { ) }\end{array}$ & $\begin{array}{l}\text { Third } \\
\text { (December } 1968 \\
\text { to } \\
\text { February 1969) }\end{array}$ \\
\hline $\begin{array}{l}\text { VII }+ \text { X } \\
\text { IX } \\
\text { X } \\
\text { Fibrinogen (mg) }\end{array}$ & $\begin{array}{r}130 \cdot 0(51) \\
109 \cdot 1(53) \\
80.3(51) \\
457 \cdot 6(53)\end{array}$ & $\begin{array}{r}128 \cdot 1(50) \\
91 \cdot 3(51) \\
82 \cdot 1(50) \\
377 \cdot 3(51)\end{array}$ & $\begin{array}{r}125 \cdot 2(54) \\
69 \cdot 0(54) \\
103 \cdot 3(54) \\
326 \cdot 5(54)\end{array}$ \\
\hline
\end{tabular}

Table II Mean values of clotting factors during each treatment period

${ }^{1}$ The number of estimations on which the mean levels are based is given in brackets. Statistical significances are given in the text. 
The treatment period effect was largely independent of the order in which the drugs were given. There were six possible drug orders and the treatment period effect was not confined to just one or two of them. The overall factor X pattern was maintained in five of the six drug order groups, the factor IX pattern in four, and the fibrinogen pattern in three. Similarly the effect was fairly consistent in all patients. The overall factor $X$ pattern was seen individually in 12 of the 18 patients, the factor IX pattern in 12, and the fibrinogen pattern in 11 . The effect was thus not limited to a small subgroup of patients or drug orders.

\section{Discussion}

The changes which occurred during treatment periods suggest either that there were seasonal variations in the levels of the coagulation factors or that laboratory standards changed, as the changes were independent of treatment and patient effects. The variation in factor $\mathrm{X}$ cannot, however, be explained by changes in laboratory technique as these assays were performed in non-temporal order at the end of the trial. In addition this trend goes in the opposite direction to the non-significant temporal changes seen in the combined factor VII-X assays which were also performed at the end of the trial. Loss of factor $\mathrm{X}$ activity on storage of plasma at $-30^{\circ} \mathrm{C}$ could explain the lower values observed in older samples but it is again difficult to see why the combined factor VII-X assays were not similarly affected.

It should be stressed that the actual treatment effects were, by virtue of the trial design, independent of the temporal effects. The results are, therefore, in no way invalidated, although interpretation of their clinical significance may be more difficult. The fact thus remains that treatment of patients with haemophilia with a combined oestrogenprogestogen preparation caused significant elevation of the factor VII-X level, whilst treatment with progestogen alone caused a less marked depression of the level of factor $X$.

Information concerning the effect of oestrogens and progestogens on blood coagulation in the male is limited. Oestrogen therapy in patients with carcinoma of the prostate has been reported to be followed by raised levels of plasma fibrinogen (Tagnon, Schulman, Whitmore, and Leone, 1953) but this may have been due to regression of secondary fibrinogenolytic deposits. Bailar (1967) noted an increased incidence of cardiovascular and cerebrovascular disease but not of pulmonary embolism in such patients. Oliver and Boyd (1961) treated patients with coronary artery disease with ethinyl oestradiol and noted no significant coagulation changes.

In females, on the other hand, there is considerable evidence that oestrogens affect blood coagulation. Poller, Tabiowo, and Thomson (1968) noted raised levels of factors VII and X even on low-dose oral contraceptives, whilst large doses of stilboestrol given to puerperal women to suppress lactation caused increased levels of factor IX (Daniel, Bloom, Giddings, Campbell, and Turnbull, 1968). Although increased fibrinogen and factor VIII has sometimes been reported it seems that the vitamin Kdependent coagulation factors are most consistently raised. Schrogie, Solomon, and Zieve (1967) have in fact suggested that vitamin $\mathrm{K}$ and oestrogen have similar physiological effects. The observation of Poller et al (1969) that a contraceptive of progestogen only caused no alteration of factors VII and X is further evidence that it is th: oestrogenic component of combined preparations which is responsible for coagulation changes.

Although oral contraceptive therapy did not benefit our haemophilic patients (Beck et al, 1970), our observations suggest that its effect on blood coagulation in males did not differ fundamentally from that observed in females. The combined preparation produced a significant rise in the factor VII-X complex and acceleration of the kaolin-cephalin clotting time (Beck et al, 1970) whilst progestogen caused no significant acceleration in the kaolincephalin clotting time and factor $X$ levels were apparently depressed. The relevance of increased clotting factors to haemostasis and thrombosis is not firmly established. Our findings, however, support the suggestion of Poller et al (1969) that progestogenic oral contraceptives may be safer in this respect than oestrogen-containing preparations.

We wish to thank Organon Laboratories Ltd for financial support, and Miss M. C. Bollard, AIMLT and Miss D. A. Thomas, AIMLT for valuable technical assistance.

\section{References}

Bailar, J. C., III (1967). Thromboembolism and oestrogen therapy. (Letter to Editor.) Lancet, 2, 560.

Beck, P., Bloom, A. L., Giddings, J. C., and Sweetnam, P. M. (1970). A controlled trial of oral contraceptives in haemophilia. Brit. J. Haematol. In press.

Biggs, R., and Macfarlane, R. G. (1962). Human Blood Coagulation and its Disorders, 3rd. ed. Blackwell, Oxford.

Daniel, D. G., Bloom, A. L., Giddings, J. C., Campbell, H., and Turnbull, A. C. (1968). Increased factor IX levels in puerperium during administration of diethylstilboestrol. Brit. med. J., 1, 801-803

Denson, K. W. (1961). The specific assay of Prower-Stuart factor and factor VII. Acta haemat. (Basel), 25, 105-120.

Donayre, J., and Pincus, G. (1965). Effect of enovid on blood clotting factors. Metabolism, 14, 418-421. 
Egeberg, O., and Owren, P. A. (1963). Oral contraception and blood coagulability. Brit. med. J., 1, 220-221.

Hardisty, R. M., and Ingram, G. I. C. (1965). Bleeding Disorders: Investigation and Management. Blackwell, Oxford.

Medical Research Council (1967). Risk of thromboembolic disease in women taking oral contraceptives: a preliminary communication to the M.R.C. by a subcommittee. Brit. med. J., 2, 355-359.

Miller, S. P., Lee, S. L., and Ritz, N. (1965). Progestin-estrogen (S.C. 11,800$)$ therapy and the hemostatic mechanism. Metabolism, 14, 398-410.

Oliver, M. F., and Boyd, G. S. (1961). Influence of serum lipids on prognosis of coronary heart-disease. Lancet, 2, 499-505.

Ozsoylu, S., and Çorbacioglu, B. (1967). Oral contraceptives for haemophilia. (Letter to Editor.) Lancet, 1, 1001

Phillips, L. L., Turksoy, R. N., and Southam, A. L. (1961). Influence of ovarian function on the fibrinolytic enzyme system. II. Influence of exogenous steroids. Amer. J. Obstet. Gynec., 82, 1216-1220.

Poller, L., Tabiowo, A., and Thomson, J. M. (1968). Effect of lowdose oral contraceptives on blood coagulation. Brit. med. J., 3, 218-219.
Poller, L., and Thomson, J. M. (1966). Clotting factors during oral contraception: further report. Brit. med.J., 2, 23-25.

Poller, L., Thomson, J. M., Tabiowo, A., and Priest, C. M. (1969). Progesterone oral contraception and blood coagulation. Brit. med. J., 1, 554-556.

Rutherford, R. N., Hougie, C., Banks, A. L., and Coburn, W. A. (1964). The effects of sex steroids and pregnancy on blood coagulation factors: a comparative study. Obstet. Gynec., 24, 886-892.

Schrogie, J. J., Solomon, H. M., and Zieve, P. D., (1967). Effect of oral contraceptives on vitamin-K-dependent clotting factor activity. (Abstr.) J. clin. Invest., 46, 1114-1115.

Tagnon, H. J., Schulman, P., Whitmore, W. F., and Leone, L. A. (1953). Prostatic fibrinolysin: study of a case illustrating role in hemorrhagic diathesis of cancer of the prostate. Amer. J. Med., 15, 875-884.

Thomson, J. M., and Poller, L. (1965). Oral contraceptive hormones and blood coagulability. Brit. med. J., 2, 270-273.

Varley, H. (1967). Practical Clinical Biochemistry, 4th ed. Heinemann, London.

\section{Reports and Bulletins prepared by the Association of Clinical Biochemists}

The following reports and bulletins are published by the Association of Clinical Biochemists. They may be obtained from The Administrative Office, Association of Clinical Biochemists, 7 Warwick Court, Holborn, London, WC1R 5DP. The prices include postage, but airmail will be charged extra. Overseas readers should remit by British Postal or Money Order. If this is not possible the equivalent of $50 \mathrm{p}$ is the minimum amount that can be accepted.

\section{SCIENTIFIC REPORTS}

3 Automatic Dispensing Pipettes. An assessment of 35 commercial instruments 1967 P. M. G. BROUGHTON, A. H. GOWENLOCK, G. M. WIDDOWSON, and K. A. AHLQUIST $85 \mathrm{p}(\$ 2)$

4 An Evaluation of 5 Commercial Flame Photometers suitable for the Simultaneous Determination of Sodium and Potassium March 1970 P. M. G. BROUGHTON and J. B. DAWSON $85 \mathrm{p}(\$ 2)$

\section{TECHNICAL BÚLLETINS}

9 Determination of Urea by AutoAnalyzer November 1966 RUTH M. HASLAM $42 \frac{1}{2} \mathrm{p}(\$ 1)$

10 Filter Fluorimeters. A comparative list of 14 instruments March 1967 HANNELORE BRAUNSBERG (Reissued in response to demand. Text still valuable, list now out of date) $42 \frac{1}{2} \mathrm{p}(\$ 1)$

11 Determination of Serum Albumin by AutoAnalyzer using Bromocresol Green October 1967 B. E. NORTHAM and G. M. WIDDOWSON $42 \frac{1}{2} \mathrm{p}(\$ 1)$

13 An Assessment of the Technicon Type II Sampler Unit March 1968 B. C. GRAY AND G. K. MCGOWAN $42 \frac{1}{2} \mathrm{p}(\$ 1)$
14 Atomic Absorption Spectroscopy. An outline of its principles and a guide to the selection of instruments May 1968 J. B. DAWSON and P. M. G. BROUGHTON $42 \frac{1}{2} \mathrm{p}(\$ 1)$

15 A Guide to Automatic Pipettes (2nd edition) June 1968 P. M. G. BROUGHTON $42 \frac{1}{2} \mathrm{p}(\$ 1)$

16 A Guide to Automation in Clinical Chemistry May 1969 P. M. G. BROUGHTON $62 \frac{1}{2} \mathrm{p}(\$ 1.50)$

17 Flame Photometers (2nd edition) 1969 P. WILDING $62 \frac{1}{2} \mathrm{p}(\$ 1.50)$

18 Control Solutions for Clinical Biochemistry (4th edition) March 1970 P. M. G. BROUGHTON $62 \frac{1}{2} p$ $(\$ 1.50)$

19 Spectrophotometers. A comparative list of low-priced instruments readily available in Britain May 1970 C. E. WILDE and P. SEWELL $62 \frac{1}{2} \mathrm{p}(\$ 1.50)$

20 Quantities and Units in Clinical Biochemistry June

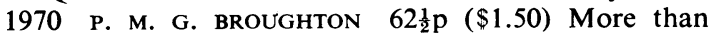
30 copies in units of 10 at $20 p$

21 Filter Fluorimeters: A comparative list of 18 instruments September $1970 \mathrm{H}$. BRAƯNSBERG and $\mathrm{s}$. $\mathrm{S}$. BROWN $62 \frac{1}{2} \mathrm{p}(\$ 1.50)$ 